Article

\title{
Impact of Assimilating Ground-Based Microwave Radiometer Data on the Precipitation Bifurcation Forecast: A Case Study in Beijing
}

\author{
Yajie Qi ${ }^{1,2}$, Shuiyong Fan ${ }^{1, *}$, Jiajia Mao ${ }^{3}$, Bai $\mathrm{Li}^{3}$, Chunwei Guo ${ }^{1}$ and Shuting Zhang ${ }^{1}$ \\ 1 Institute of Urban Meteorology, China Meteorological Administration, Beijing 100089, China; \\ yjqi@ium.cn (Y.Q.); cwguo@ium.cn (C.G.); stzhang@ium.cn (S.Z.) \\ 2 Key Laboratory for Cloud Physics of China Meteorological Administration, Beijing 100081, China \\ 3 Meteorological Observation Center of China Meteorological Administration, Beijing 100081, China; \\ maojj@cma.gov.cn (J.M.); Libai@cma.gov.cn (B.L.) \\ * Correspondence: syfan@ium.cn
}

check for

updates

Citation: Qi, Y.; Fan, S.; Mao, J.; Li, B.; Guo, C.; Zhang, S. Impact of Assimilating Ground-Based

Microwave Radiometer Data on the Precipitation Bifurcation Forecast: A Case Study in Beijing. Atmosphere 2021, 12, 551. https://doi.org/ 10.3390/atmos12050551

Academic Editor: Sergio

Fernández-González

Received: 29 March 2021

Accepted: 21 April 2021

Published: 25 April 2021

Publisher's Note: MDPI stays neutral with regard to jurisdictional claims in published maps and institutional affiliations.

Copyright: (c) 2021 by the authors. Licensee MDPI, Basel, Switzerland. This article is an open access article distributed under the terms and conditions of the Creative Commons Attribution (CC BY) license (https:/ / creativecommons.org/licenses/by/ $4.0 /)$.

\begin{abstract}
In this study, the temperature and relative humidity profiles retrieved from five groundbased microwave radiometers in Beijing were assimilated into the rapid-refresh multi-scale analysis and prediction system-short term (RMAPS-ST). The precipitation bifurcation prediction that occurred in Beijing on 4 May 2019 was selected as a case to evaluate the impact of their assimilation. For this purpose, two experiments were set. The Control experiment only assimilated conventional observations and radar data, while the microwave radiometers profilers (MWRPS) experiment assimilated conventional observations, the ground-based microwave radiometer profiles and radar data into the RMAPS-ST model. The results show that in comparison with the Control test, the MWRPS test made reasonable adjustments for the thermal conditions in time, better reproducing the weak heat island phenomenon in the observation prior to the rainfall. Thus, assimilating MWRPS improved the skills of the precipitation forecast in both the distribution and the intensity of rainfall precipitation, capable of predicting the process of belt-shaped radar echo splitting and the precipitation bifurcation in the urban area of Beijing. The assimilation of the ground-based microwave radiometer profiles improved the skills of the quantitative precipitation forecast to a certain extent. Among multiple cycle experiments, the onset of 0600 UTC cycle closest to the beginning of rainfall performed best by assimilating the ground-based microwave radiometer profiles.
\end{abstract}

Keywords: ground-based microwave radiometer; weak heat island effect; the precipitation bifurcation

\section{Introduction}

Ground based microwave radiometer is meteorological observation instrument based on remote sensing technology. Its primary data are brightness temperature data, which represents electromagnetic wave signal received by radiometer at specified frequency. They are a kind of unconventional observation data. The secondary data of atmospheric temperature and humidity profiles and cloud and precipitation information are obtained through inversion calculation. So far, level-2 of ground-based microwave radiometer products have provided continuous temperature and humidity profiles at a high time frequency [1-3], providing valuable information to follow the evolution of the boundary layer.

Its products have been extensively applied to many fields, such as liquid water path inversion for weather modification, boundary layer height inversion for air quality monitoring and prediction [4,5], water vapor characteristics analysis, and environmental meteorological conditions for haze maintenance [6-9]. The continuous and stable temperature and humidity profiles provided by the ground-based microwave radiometer effectively have overcome the deficiency of the conventional radiosonde in obtaining atmospheric information due to the long observation interval. Previous studies have shown 
that the ground-based microwave radiometer can be assimilated and applied to numerical prediction and that it has different impacts on the prediction.

The ground-based microwave radiometer observations have been playing an increasingly important role in numerical weather prediction systems. However, the assimilation of the microwave radiometers into numerical weather prediction systems has been limited to a few sporadic attempts [10]. For example, Vandenberghe and Ware (2002) assimilated the temperature and humidity profile data of the single station ground-based microwave radiometer into MM5, effectively improved the prediction of winter fog [11]. Assimilating the ground-based microwave radiometer data into WRF had a positive impact on the prediction of temperature and humidity analyses, whereas the impact on precipitation accumulation forecasts was more obvious [12,13]. Caumont et al. (2016) assimilated the profiles retrieved by multiple ground-based microwave radiometers into the mesoscale prediction system, the results showed that the impact was neutral and only works for large-scale precipitation [12]. In a rainstorm process, the relative humidity profiles retrieved by three ground-based microwave radiometers were assimilated, and the results show that the prediction of precipitation intensity was significantly improved, but that of precipitation distribution was not [14]. Data of two ground-based microwave radiometers were assimilated rainstorm in Beijing on in July 20 in 2016. It proved that the microwave radiometers data assimilation improved the prediction of the intensity and distribution of precipitation in its early stage [15].

It is very challenging to obtain high-quality precipitation estimates. For blending multi-satellite, atmospheric reanalysis, and gauge precipitation products, the distribution of observations are unevenly and sparsely and the precipitation estimates based solely on observations are subject to large uncertainties $[16,17]$. The machine learning algorithms have been applied to merge Satellite-based precipitation products and observations to improve the accuracy of the precipitation estimates in recent years. For instance, Kumar (2019) corrected the near-real-time multi-satellite precipitation analysis-based product by combining it with soil moisture through a support vector machine based regression model [18]. Bhuiyan et al. (2020) employed the random forest and neural networks to generate an error-corrected product [19]. Zhang et al. (2021) proposed a novel double machine learning approach to merge multiple satellite-based precipitation products and observations [17]. Yagmur (2020) developed tree-based quantile regression to reduce precipitation retrieval error [20].

For the accuracy of precipitation forecasts produced by a numerical model, it is greatly influenced by the initial states of the atmosphere, especially for the short-term forecast system [21]. The prediction of a definite numerical model is subject to the accuracy of its initial field. From this view, there is a particular need for more in-situ observations on the profiles of atmospheric meteorological element. These are important for initialization of numerical weather prediction models [22-24]. Data assimilation combines the observation data with the background field of the model to produce more accurate initial values, which will contribute to improve the meteorological element prediction and the development of the precipitation system [25-27]. The variational method considers the system as a whole and combines the model and observations in a statistically optimal sense [27]. It is currently widely used in research communities and operational centers. The WRF data assimilation system WRFDA included the three-dimensional variation, four-dimensional variation, and hybrid techniques at the National Center for Atmospheric Research [28-30]. The three-dimensional variation method is often used in the assimilation filed, owing to its low calculation cost, small resource occupation, and high efficiency. The 3DVAR framework is generally easier for implementation in operational runs.

Previous studies have made insightful exploration into the application of groundbased microwave radiometer data in the numerical model. However, few researchers focused on the application of assimilating ground-based microwave radiometer data to regional operational forecast over North China. In particular, for Beijing, being embraced on three sides by mountains, the urban heat island effect, coupled with other factors, 
increase the difficulty and uncertainty of its precipitation forecast. Currently, although the weather-forecasting technology is capable of forecasting rainfall caused by large-scale weather systems, it is incapable of forecasting local rainfall and does not perform as required with respect to people's life and production activities, especially in the urban area [31,32]. Thus, reproducing observed urban effect on rainfall can help increase the accuracy of rainfall forecasting in Beijing.

In this study, the temperature and humidity profiles retrieved from five groundbased microwave radiometers in Beijing are assimilated into the rapid-refresh multi-scale analysis and prediction system-short term (RMAPS-ST). The impact of the ground-based microwave radiometers data on the analyses and forecasts of this splitting process in Beijing are evaluated. Assimilation experiments are carried out in this study. Combined with comparative analysis, we explore the effect of assimilation of ground-based microwave radiometer data on the prediction of the precipitation bifurcation in Beijing. Through the experiments, we aim to advance urban fine weather forecast to serve urban operation while helping public production with their daily activities by providing better information.

The rest of this paper is structured as follows. Section 2 introduces the belt-shaped echo splitting case examined for this study, the characteristics of ground-based microwave radiometer data and the experimental setting. In Section 3, the impact of assimilated ground-based microwave radiometer data on both analysis field and the prediction of beltshaped convection splitting are compared, for the continuously cycling data assimilation and forecasting experiments. The diagnosis for this rainfall bifurcation event with and without the data assimilation of the ground-based microwave radiometers are discussed in Section 4. Finally, conclusions are presented in Section 5.

\section{Materials and Methods}

\subsection{Belt-Shaped Echo Splitting Case}

In the present study, we take the echo splitting process in Beijing on 4 May 2019 as an example to investigate whether the assimilation of ground-based microwave radiometer data could improve precipitation simulation. The evolution of belt-shaped echo in this process is shown in Figure 1. At 0400 UTC (Coordinated Universal Time) on 4 May 2019, a northeast and southwest belt-shaped echo emerges in Inner Mongolia, followed by convection. The strong echo belt moves rapidly to the southeast, reaches Beijing at 0900 UTC, and splits at 1000 UTC when it approaches the urban area of Beijing. Within the urban area, the echo weakens and dissipates. The echo in the northern and southern parts of the urban area continues to move southeast before it disappears at 1100 UTC. The weather process spanned a period of $7 \mathrm{~h}$. It is characterized by the belt-shaped echo splitting in the periphery of Beijing, during which no precipitation occurs in the urban area of Beijing when it moves from northwest to southeast (Figure 1).

\subsection{Data Processing of Ground-Based Microwave Radiometer}

A total of seven microwave radiometers are deployed in Beijing during the metropolitan observation experiments. Data of the two microwave radiometers deployed in Haidian District and Shangdianzi Village (in Miyun District) is missing due to equipment problems, while that of the remaining five microwave radiometers deployed in Xiayunling Village (in Fangshan District), Yanqing District, southern suburb, Huairou District, and Pinggu District is available. The five level-2 ground-based microwave radiometer products in Beijing are obtained by the inversion software from microwave radiometer manufacturers, including the temperature and relative humidity profiles. The continuous observations of temperature and humidity profiles are high temporal resolution (at a high frequency rate up to two minutes). 

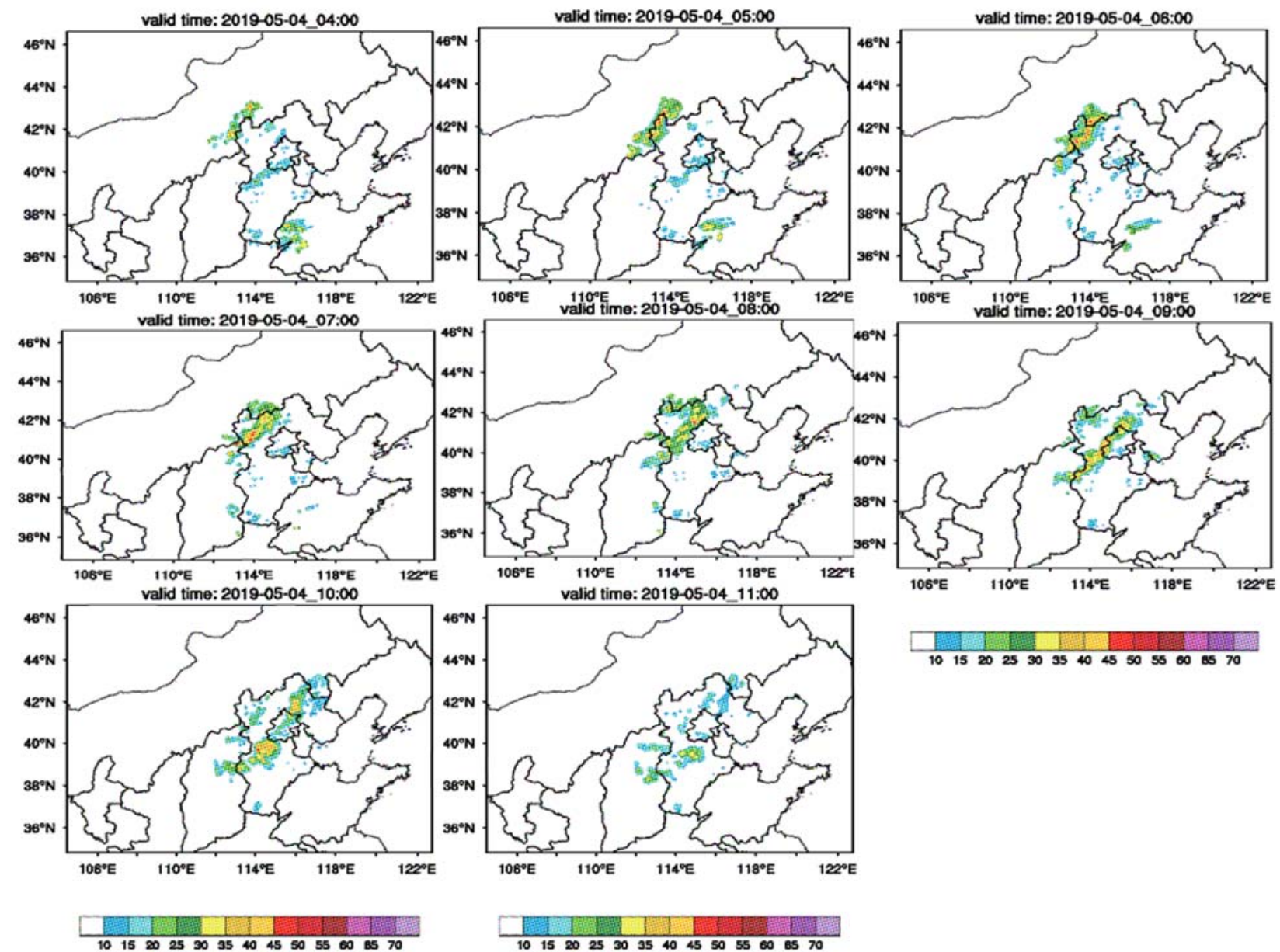

Figure 1. Radar composite reflectivity (CREF) evolution for belt-shaped zone in North China on 4 May 2019.

Figure 2 shows the vertical distribution of retrieved temperature and humidity profiles at each station, as well as their evolution with time. It reveals that microwave radiometers overcome the spatial and temporal shortcomings of conventional observation, especially temporal ones. Prior to the three-dimension variation assimilation, the temperature profile and relative humidity profile data retrieved by microwave radiometer at $0-10 \mathrm{~km}$ height are processed. Since precipitation has great impact on temperature and relative humidity retrieved by microwave radiometer, the observation data of radiometer during precipitation should be prudently dealt with. In this paper, the data at the corresponding time of precipitation are set as missing value. In addition, as the temperature and humidity profiles retrieved by microwave radiometers at $0-10 \mathrm{~km}$ height are of high vertical resolution, the reference atmospheric pressure at each height layer from 0 to $10 \mathrm{~km}$ is calculated by the formula [33]. 

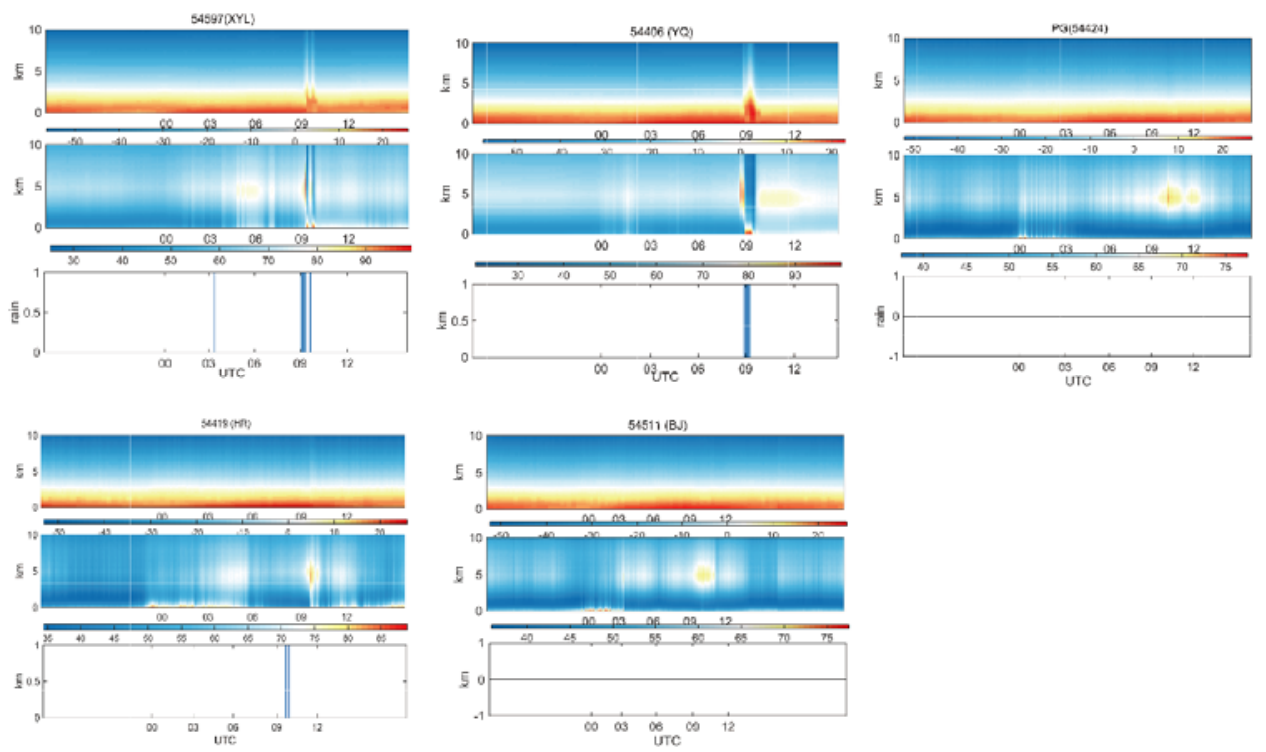

Figure 2. Time-height profile of temperature and humidity profile of five ground-based microwave radiometers in Beijing on 4 May 2019 and the judgment of precipitation at corresponding time from the MWRPS located in Xiayunling; Yanqing, Pinggu, Huairou, and Southern suburb of Beijing. Note: the blue bar indicates the period of rain in the ground-based microwave radiometer observations.

\subsection{Experiment Design}

In this study, an experiment is carried out, using RMAPS-ST numerical forecast model. The model, based on the previous generation of North China rapid-refresh cyclic assimilation and forecast system [34,35] is a short-term forecasting subsystem of a new generation of RMAPS developed by Institute of Urban Meteorology, CMA, Beijing. It has been in operation since May 2017 [36]. The RMAPS-ST features double nesting, ninekilometer-resolution outermost D01 area with $649 \times 500$ grid points covering the whole China, and three-kilometer-resolution inner D02 area with the innermost $550 \times 424$ grid points in the simulated area covering North China. The parameterized schemes of main physical process of the experiment include a new Thompson cloud microphysics scheme, NOAH land surface scheme, Yonsei University (YSU) boundary layer scheme [37], the global parameterization of the Rapid Radiative Transfer Model (RRTMG) scheme [38,39]. In this paper, ECMWF medium-range forecast $\left(0.25^{\circ} \times 0.25^{\circ}\right)$ is selected to provide the initial field and side boundary conditions for the model. Having gone through quality control, the observed data, including conventional data and radar data, are input into the assimilation system. Most of these conventional data are collected every hour. Radar data are collected at the frequency rate of six minutes and the radar data assimilation is performed, including radial velocity and reflectivity. Owing to low calculation cost, small resource occupation and high efficiency, the three-dimensional variational data assimilation system (3DVar) of the Weather Research and Forecasting model system is adopted. The solution of 3DVar can be interpreted as obtaining the minimization of the objective function. Based on the optimization theory, the optimal solution is obtained by iterative descent algorithm. Specifically, the optimal state of the atmosphere is estimated by using both the background field and observed values, thus the statistical optimal analysis is obtained. When $\mathrm{U}$ and $\mathrm{V}$ are used as dynamic control variables, the correlation between variables is smaller than that when traditional flow function and potential function control variables are used, which satisfies the assumption of variational data assimilation. Such algorithm is more conducive to the description of medium and small-scale systems [40]. Background error covariance is calculated by the National Meteorological Center (NMC) method [41]. The system runs eight times a day at 0000 UTC, 0300 UTC, 0600 UTC, 0900 UTC, 1200 UTC, 1500 UTC, 1800 UTC, and 2100 UTC, respectively. At 0000 UTC, the system starts in the 
mode of Partial Cycle [42], that is, the initial field is the 6-h forecast field of 1800 UTC the previous day; afterwards the initial field is driven by the 3 -h forecast field of the previous time level.

In total, two groups of experiments are designed, that is, the Control experiment and the MWRPS experiment. The Control experiment assimilates conventional observation data and Beijing-Tianjin-Hebei weather radar data. Different types of conventional observations are incorporated into the system to improve the analysis for both domains, including aircraft meteorological data relay, synoptic, sounding, oceanographic buoys, and ship-based observations (Figure 3). Radar data assimilation are mainly in Domain 2 of the system, including radial velocity and reflectivity. Based on the Control experiment, the MWRPS experiment adds the data of five microwave radiometers in Beijing. The data distribution is shown in Figure 3. We compare the differences between the experimental results with and without the ground-based microwave radiometer data assimilation for analysis.

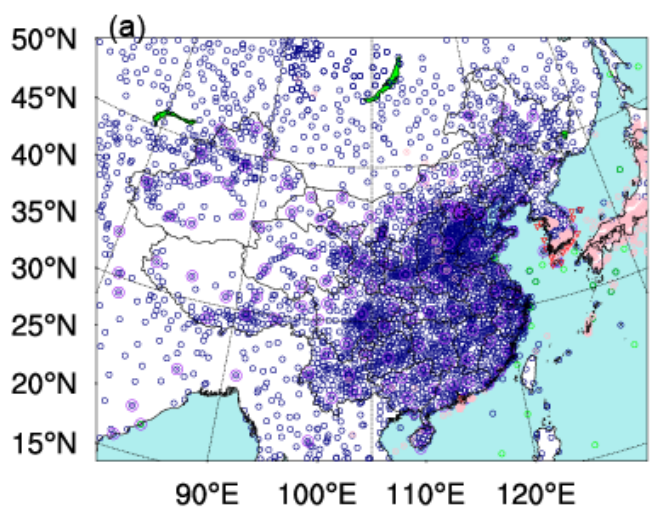

(b)

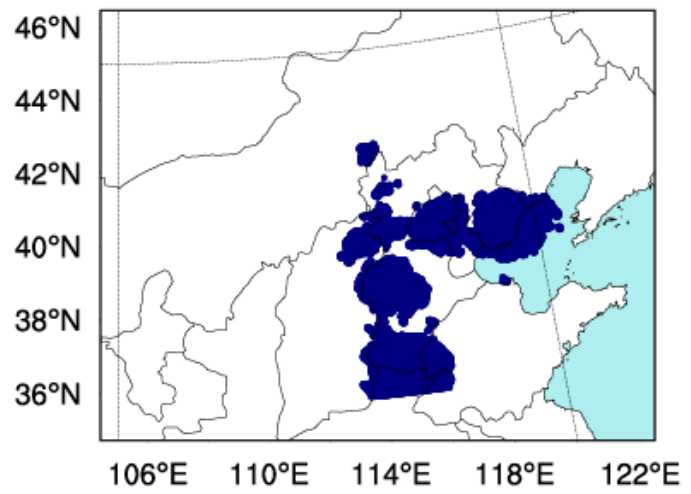

(c)

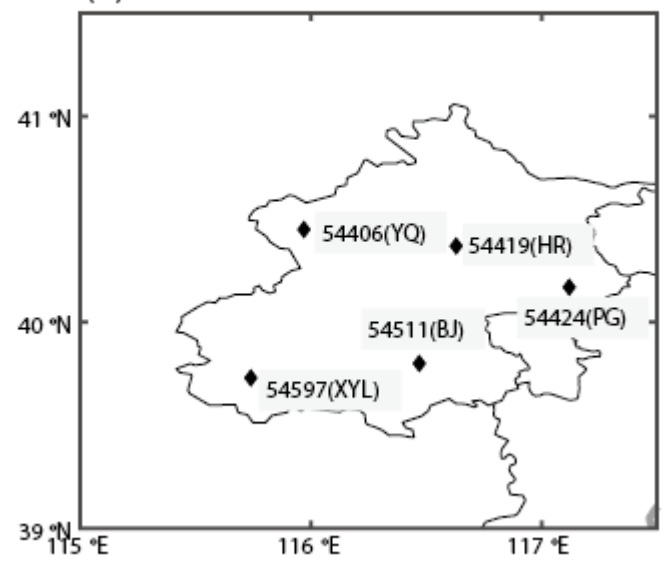

Figure 3. Spatial distribution of the assimilated observations at 0000 UTC. (a) In Domain 1 of RMAPS-ST, locations of radiosonde launch sites used are represented as purple solid circles, oceanographic buoys and ship-based observations are represented as red circles and green circles, Dark blue circles and pink circles indicate, respectively, synoptic and aircraft meteorological data relay whenever available at 0000 UTC 4 May 2019. (b) Domain 2 and the radar locations marked as dark blue solid circles. (c) Locations of MWRPS sites used in this study are also shown, represented as black diamond.

Each group of experiments performs a cold start from 1800 UTC on 3 May 2019, and predicted for six hours to obtain the forecast field at 0000 UTC on 4 May 2019, which is used as the background field to assimilate the observed data. Then, 0300 UTC is driven by the 3-h forecast field of 0000 UTC, and the 0600 UTC experiment is driven by the 3-h forecast field of 0300 UTC (see Figure 4 for the test flow). The two-step assimilation 
method of RMAPS-ST is carried forward. In the first step, conventional data and groundbased microwave radiometer data are assimilated; in the second step, radar observations are assimilated.

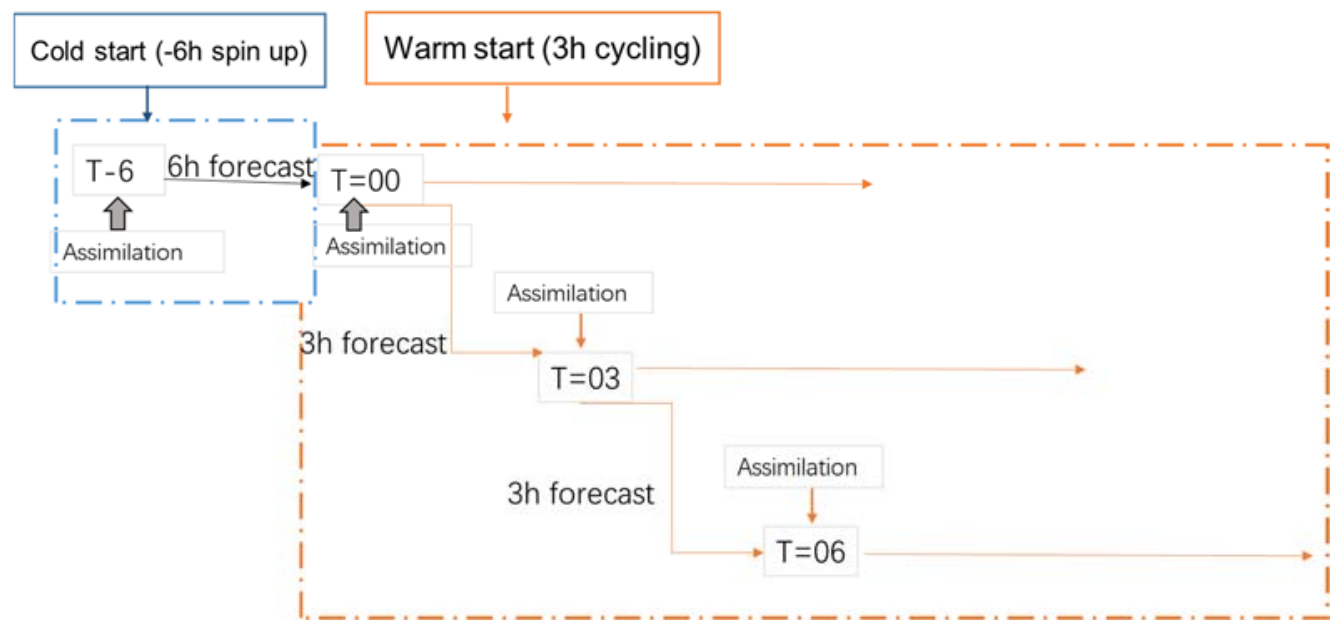

Figure 4. A schematic of data assimilation and forecast experiments in the RMAPS-ST.

\section{Results}

\subsection{Impact of Assimilated Ground-Based Microwave Radiometer Data on Analysis Field}

Data assimilation provides the initial field for the numerical model, which makes the calculation results of the model more accurate. To verify the impact of MWRPS data assimilation on the initial field, we take the initial report test at 0600 UTC as an example and compare the temperature and humidity profiles of observation, background field and analysis field at Station 54419 (Shangdianzi) and Station 54511 (southern suburb) (Figure 5). At 0600 UTC (1400 Beijing time), at Station 54419 the near-surface air temperature is slightly lower and the near-surface specific humidity is slightly higher than those at Station 54511. Compared with the background field, the analysis field of assimilation experiment of ground-based microwave radiometer data is closer to the observation in almost all atmospheric layers. For example, the temperature in the lower layer below $850 \mathrm{hpa}$ at Station 54419 is high, and that in the upper layer at Station 54511 is low. The analysis field corrected the warm bias in the lower layer and the cold bias in the upper layer of the background field, which was closer to the observation. For the specific humidity of the whole atmosphere, its background field is dry in the bottom layer and layers above $700 \mathrm{hpa}$, wet in middle and lower layers at both Station 54419 and Station 54511. The specific humidity of the assimilated ground-based MWRPS test also corrects the deviation, which was closer to the observation. The temperature and humidity profiles of the analysis fields in the other three ground-based MWRPS stations, compared with those of the background field, are closer to the observations (figure omitted). Overall, MWRPS data can improve the similarity between analysis field and the observation field in terms of temperature and humidity profiles. 


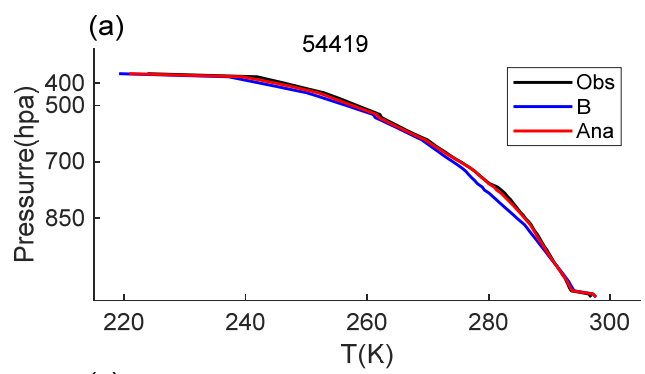

(c)

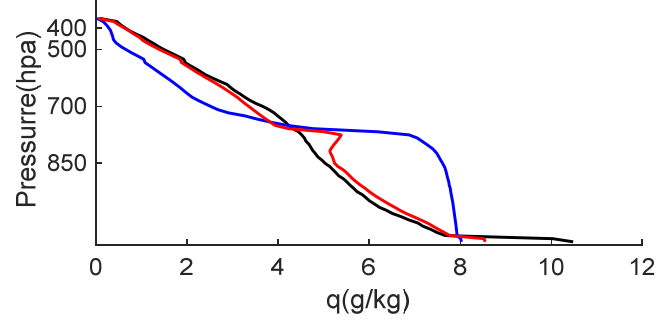

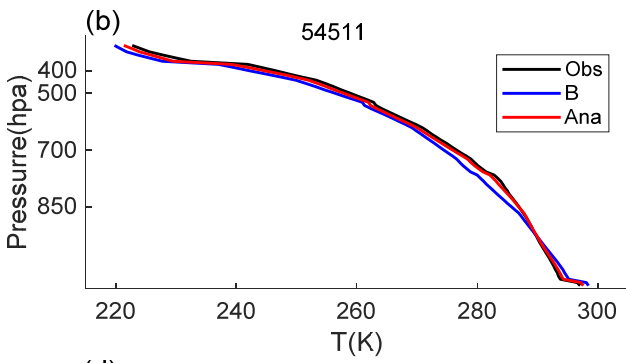

(d)

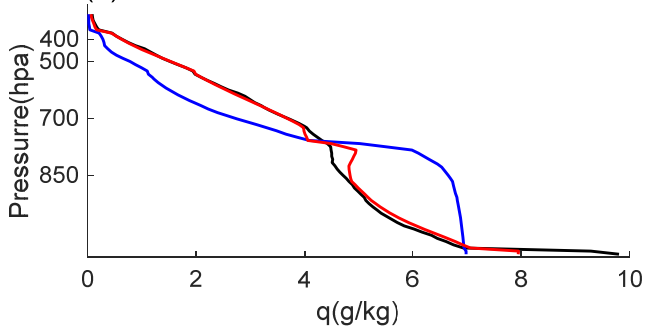

Figure 5. (a,b) Vertical profiles of the temperature profiles (K) from observation (black lines), background (blue lines) and analysis (red lines) at verification station $(54419,54511)$; and $(\mathbf{c}, \mathrm{d})$ the specific humidity profiles $\left(\mathrm{g} \mathrm{kg}^{-1}\right)$ at analysis time (0600 UTC, 4 May 2019).

3.2. Impact of Ground-Based Microwave Radiometer Data Assimilation on Belt-Shaped Convection Splitting Prediction

Based on the analysis field formed by assimilation in the two experiments in Section 3.1, we compare the prediction results after assimilation. For the phenomenon of the beltshaped echo splitting in Beijing on 4 May 2019, the radar reflectivity simulations at 1000UTC of the two groups of experiments are compared. Figure 6 shows the simulated radar reflectivity in the MWRPS and Control experiments, the left side shows the simulation results obtained from the MWRPS case, initialized at 0000 UTC, 0300 UTC, and 0600 UTC, respectively, whereas the right side shows the simulation results obtained from the Control case. Generally, the radar echo zone corresponds to the location of a convection cell and the radar reflectivity intensity corresponds to the convection intensity in the convection cell.

The three-cycle prediction in the Control test has no prediction ability for the observed belt-shaped echo splitting phenomenon, neither could the MWRPS test be valid from 0000 UTC. In contrast, the MWRPS tests valid from 0300 UTC and 0600 UTC could better simulate the observed belt-shaped convection splitting process: the MWRPS test produces satisfactory simulation results in terms of the location and intensity of the convection cells when the system affects the urban area of Beijing. Accordingly, it could obviously has better approaching prediction ability when belt-shaped echo splitting occurs. For the prediction ability of both the intensity and the range of the simulated radar reflectivity, 0300 UTC and 0600 UTC test in MWRPS were quite closer to the actual situation, compared to the MWRPS experiment valid from 0000 UTC.

The development of the convection cells in a rainfall system directly impact the development of precipitation. Both the intensity and distribution of rainfall are closely related to the intensity of the nearby convection cells. To examine the improvement in precipitation forecast, the 1-h accumulated precipitation from the observation, MWRPS experiment and Control experiment was compared (Figure 7). By comparing the precipitation forecast through observation and two experiments, we find that the assimilated data of the ground-based microwave radiometers are superior to the Control test in 1-h accumulated precipitation simulation, testified mainly in the following aspects. 

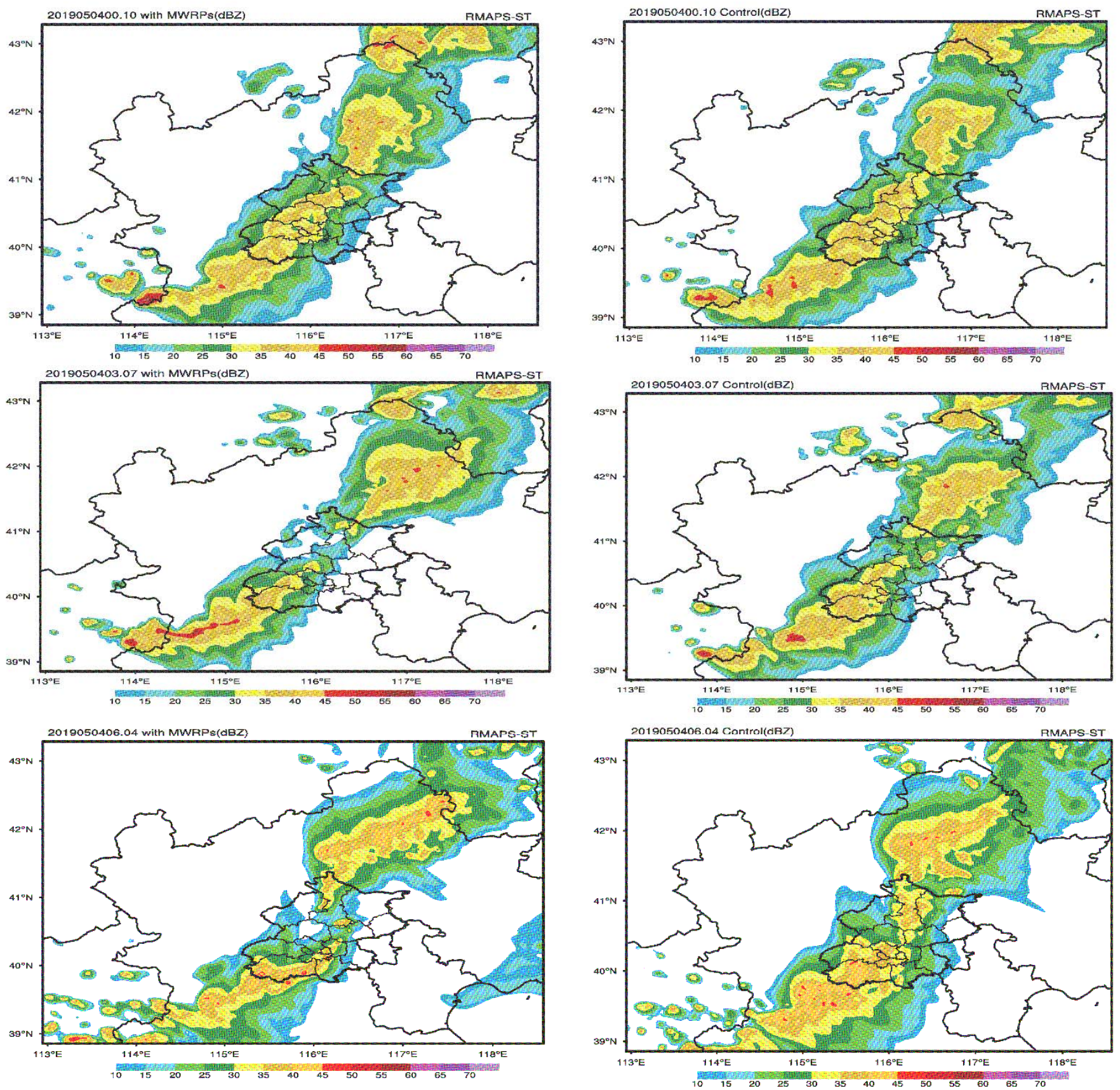

Figure 6. Composite radar reflectivity (unit: dBZ) of 1000 UTC on 4 May 2019 simulated by MWRPS test (first column) and Control test (second column) valid from 0000 UTC, 0300 UTC, 0600 UTC from top to bottom (Beijing-Tianjin-Hebei region), as labeled over the upper left corner of each subplot. 


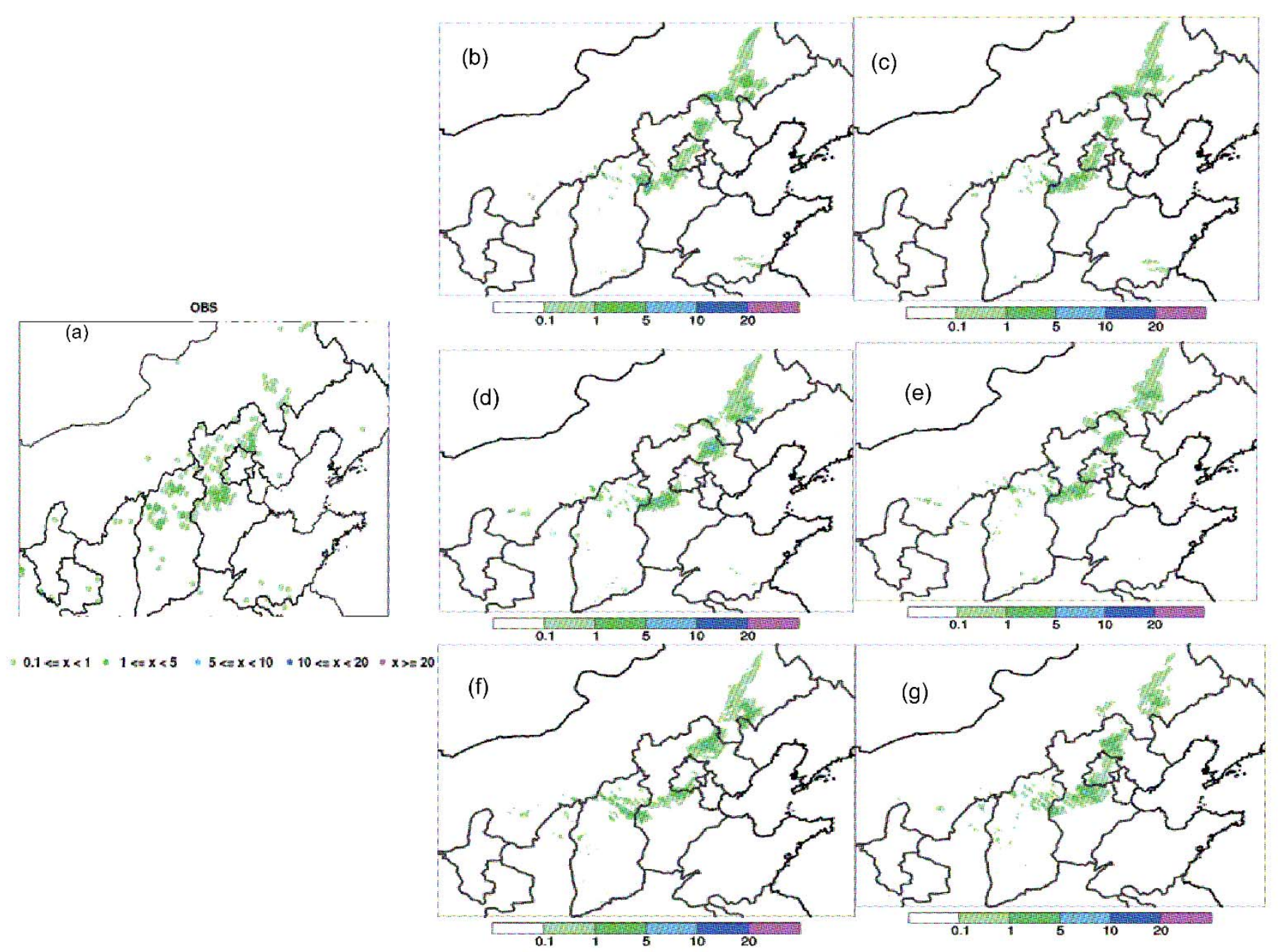

Figure 7. Distribution of forecasts of 1-h accumulated precipitation between 1000 UTC and 1100 UTC on 4 May 2019 estimated by observation based on ground stations (a); forecasted by MWRPS simulations initialized at 0000 UTC (b), 0300 UTC (d), 0600 UTC (f) on 4 May 2019; forecasted by Control simulations initialized at 0000 UTC (c), 0300 UTC (e), 0600 UTC (g) on 4 May 2019.

Firstly, the belt-shaped echo splits in the periphery of Beijing at 1000 UTC, and no precipitation is reported in Beijing from the observation (Figure 7a). Compared with the Control test, the MWRPS test could deliver prediction closer to the actual condition and better in the forecast of precipitation distribution. Secondly, the hourly precipitation intensity predicted by the MWRPS test assimilating the ground-based microwave radiometer data are closer to the observation (Figure 7f). Regarding the prediction of the precipitation intensity of Baoding, Hebei Province valid from 0600 UTC, the MWRPS test shows a result consistent with the observation while the Control test reports a result one level higher than the observation (Figure 7f,g). Thirdly, as can be seen from Figure $7 \mathrm{~b}, \mathrm{~d}, \mathrm{f}$, the precipitation positions predicted by the MWRPS tests valid from both 0300 UTC and 0600 UTC are quite consistent with the observation, proving that the prediction at the above two time levels could represent the precipitation bifurcation phenomenon in Beijing. The simulation of precipitation intensity by the MWRPS test valid from 0600 UTC is the closest to the observation. Especially, in Baoding, the intensity center, the precipitation intensities predicted by the MWRPS test valid from 0000 UTC and 0300 UTC are higher than the observations. The precipitation predicted by the test valid from 0300 UTC ranges from $5 \mathrm{~mm} \mathrm{~h}^{-1}$ to $10 \mathrm{~mm} \mathrm{~h}^{-1}$ (Figure 7d).

The MWRPS test valid from 0600 UCT displays the strongest simulation impact on precipitation bifurcation in Beijing caused by belt-shaped convection splitting. Overall, the forecast precipitation in MWRPS during the assimilation period shows significant im- 
provement compared with the Control experiment. Both the composite reflectivity and the 1-h accumulated precipitation of the observation, Control, and MWRPS experiment were compared, showing the improvement in the forecast with the ground-based microwave radiometer data assimilation. Therefore, the subsequent analysis is centered around two groups of experiments valid from 0600 UTC.

3.3. Impact of Ground-Based Microwave Radiometer Data Assimilation on Meteorological Element Prediction before Belt-Shaped Convection Splitting

Owing to the joint effects of topography and urban thermal circulation, the urbanization process was significant in Beijing-Tianjin-Hebei collaborative development area [43], precipitation in Beijing has its uniqueness and complexity [44-46]. Previous studies have shown that the intensity of urban heat island prior to the start of rainfall could project, to a certain extent, the thermodynamic impact of urban underlying surface on the precipitation process. Under the effect of strong heat island, the thermodynamic process prevails, making precipitation concentrate in urban areas. Under the effect of weak heat island, urban dynamics prevails. Hence, precipitation bifurcation takes place, making precipitation mainly distributed in the upwind direction of the city and on both sides of the city $[43,47,48]$. Thus, the heat island intensity prior to the start of rainfall determines the kind of urban effects on rainfall.

Figure 8 shows the spatial distribution of $2 \mathrm{~m}$ air temperature observed at 09: 00 UTC before the echo moved to the urban area in Beijing. Referring to Zhang et al. (2017), we select black rectangular boxes to identify the heat island intensity and make statistical analysis. At 0900 UTC, this region, including urban and suburban areas in Beijing, report no precipitation. It can be seen that before the belt-shaped echo moves to the urban area of Beijing, there is no obvious difference between the urban temperature in the Fifth Ring Road and that in its surrounding area. The heat island intensity in Beijing is weak [43].

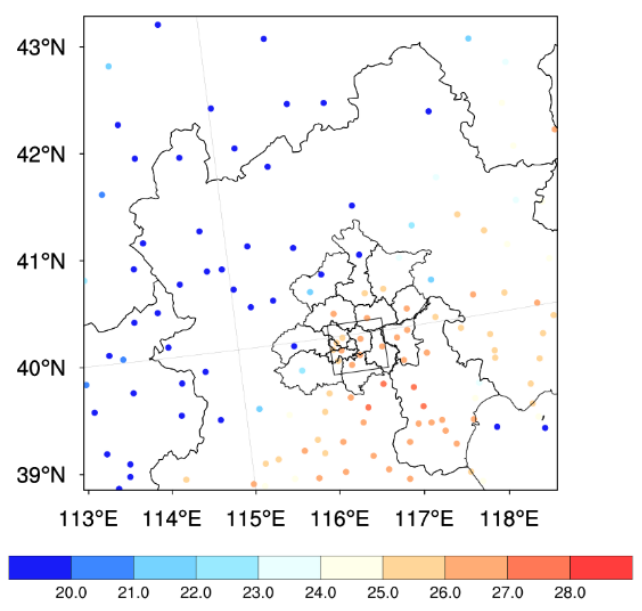

Figure 8. Spatial distribution of observed air temperature at $2 \mathrm{~m}$ (unit: ${ }^{\circ} \mathrm{C}$ above the ground of 0900 UTC on 4 May 2019. Note: the black rectangle box indicate the area $\left(116.12^{\circ} \mathrm{E}-116.79^{\circ} \mathrm{E}, 39.65^{\circ}\right.$ $\mathrm{N}-40.115^{\circ} \mathrm{N}$ ) in which temperature prior to the start of rainfall is statistically analyzed.

As indicated by the spatial distribution of $2 \mathrm{~m}$ temperature bias at 0900 UTC predicted by the two groups of experiments (Figure 9a,b), the temperature deviation predicted by the Control test in and around Beijing's Fifth Ring Road (black rectangular frame) is larger than that by the MWRPS test. Especially, the Control test overestimates the observed heat island intensity in the urban area within the Fifth Ring Road. The assimilated data of the ground-based microwave radiometers corrected the warm bias in this area, and the modified indexes $\mid$ Bias $_{M W R P S}|-|$ Bias $_{\text {Control }} \mid$ of $2 \mathrm{~m}$ air temperature are all negative, which is closer to the observation (Figure 9c). 

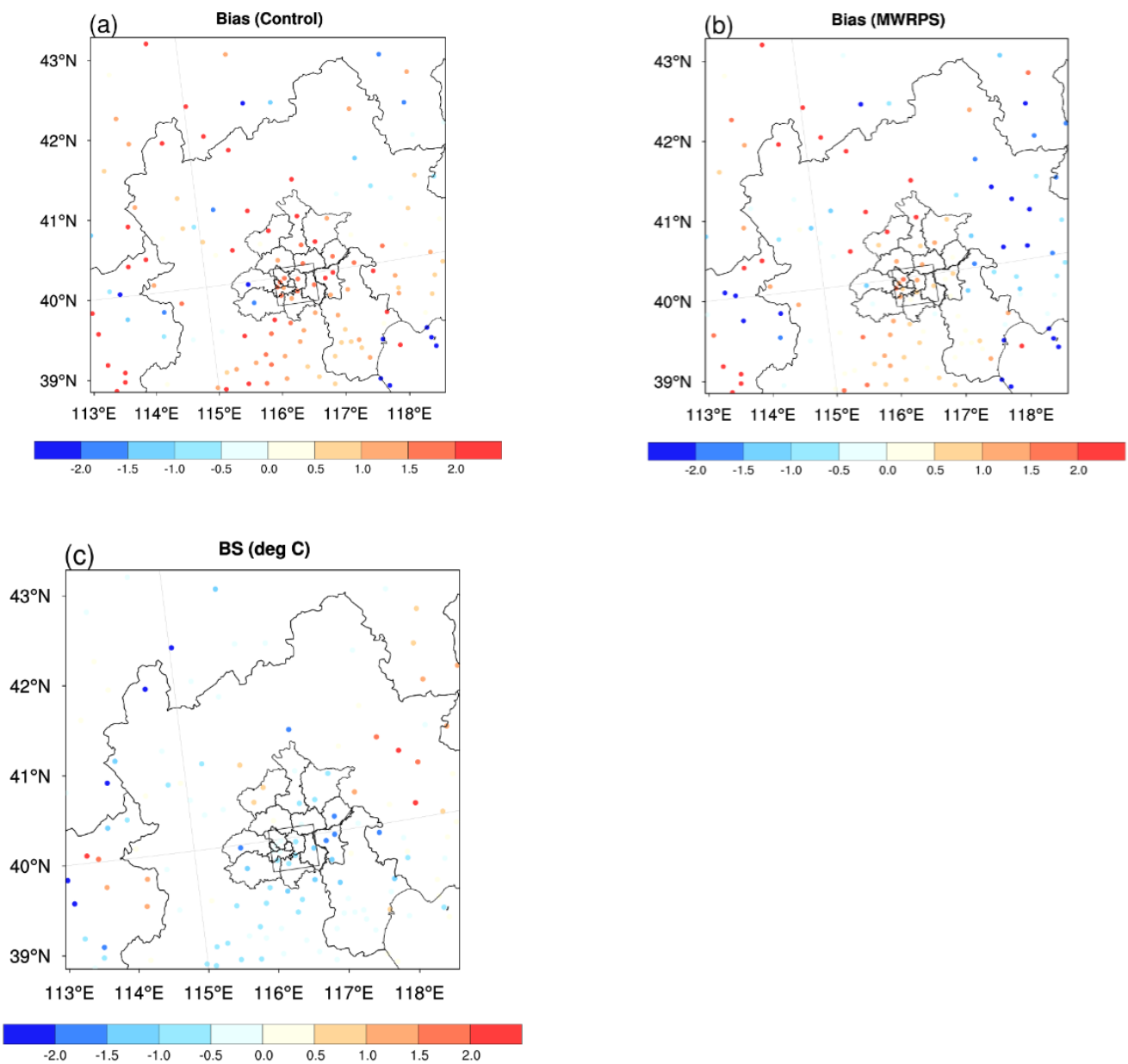

Figure 9. $(\mathbf{a}, \mathbf{b})$ The bias of $2 \mathrm{~m}$ temperature (unit: ${ }^{\circ} \mathrm{C}$ ) simulated by Control experiment (Control minus Observation) and the bias of $2 \mathrm{~m}$ temperature simulated by MWRPS experiment (MWRPS minus Observation) before belt-shaped echo splitting and (c) improving index (unit: ${ }^{\circ} \mathrm{C}$ ) after assimilating ground-based microwave radiometer at 0900 UTC on 4 May 2019.

The MWRPS test improves the prediction performance of $2 \mathrm{~m}$ temperature in Beijing, and better reproduces the observed weak heat island phenomenon. Thus, the observed rainfall bifurcation can be simulated in the MWRPS experiment, due to the main effect of urban surface in Beijing on rainfall through its dynamic action under low urban heat island conditions.

\section{Discussion}

Furthermore, we compare the temperature difference in both the bottom layer and the high layer from analysis fields of the two experiments initialized at 0600 UTC 4 May 2019. We find that negative difference in the bottom layer and positive difference in the high layer in Beijing where the data of ground-based microwave radiometers are assimilated. Compared with the Control test, the MWRPS test has thermal changes in low-level cooling and high-level heating (Figure 10) in its analysis field. The data assimilation of the groundbased microwave radiometers makes the atmospheric stratification of the initial field in this area more stable, and the analysis field lacks the environment support to the emergence and development of convection, which is not conducive to the emergence of precipitation. The ground-based microwave radiometer leads to the cooling of the bottom layer in Beijing in the analysis field of the MWRPS test (Figure 10). The system modifies the initial field in time, thus affecting the prediction of air temperature. 

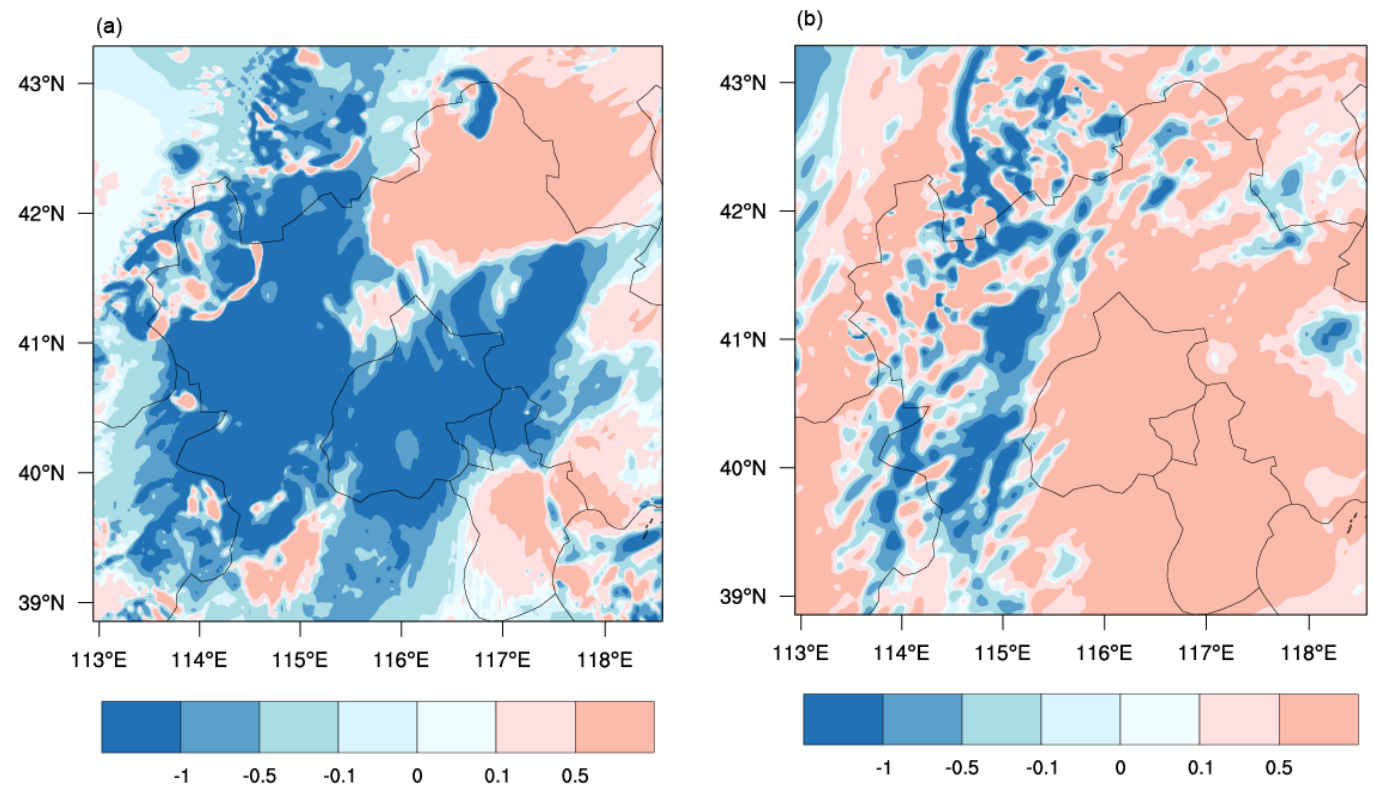

Figure 10. (a) Temperature field difference between MWRPS test and Control analysis (MWRPS minus Control, model level = 1) valid from 0600 UTC on 4 May 2019 (Beijing-Tianjin-Hebei region); (b) the same to (a), but for Level 27 of the model.

Figure 11 shows the radial vertical profile of temperature and vertical velocity along $40^{\circ} \mathrm{N}$ in the boundary layer of the Fifth Ring Road and its surrounding areas in the analysis field of two groups of experiments initialized at 0600 UTC on 4 May 2019. It can be seen that the heat island simulated by the Control experiment is too strong, producing strong updrafts in the urban area. A clear updraft was found leading to a rainfall forecast in Control experiment. This urban ascending motion is strengthened under the strong heat island effect, which promotes the emergence of updrafts. The heat island effect simulated by the MWRPS test assimilating the ground-based microwave radiation data in Beijing is weak. The sinking-motion-dominant boundary layer inhibits the emergence and development of convection and accordingly affects the forecast of urban precipitation. The vertical velocity simulated by MWRPS experiment is negative and the ascending motion decreases, thus the simulated precipitation is reduced. It suggested that the ground-based microwave radiometer observations provide more beneficial information for the initial conditions and indirectly weaken the local updraft in the urban area in Beijing, consequently improve the rainfall bifurcation forecasts.
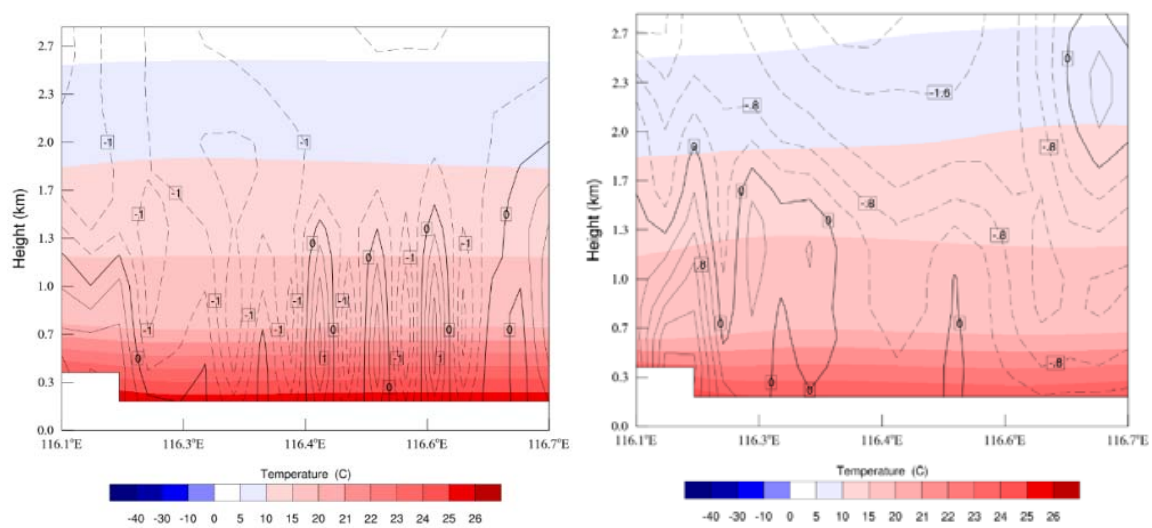

Figure 11. Left and right figures are cross sections of the vertical profiles along $40^{\circ} \mathrm{N}$ from Control and MWRPS analysis field initialized at 0600 UTC on 4 May 2019, in which the contour represents the vertical velocity (unit: $10^{-1} \mathrm{~m} / \mathrm{s}$ ), and the shaded represents the temperature (unit: ${ }^{\circ} \mathrm{C}$ ). 
Additionally, the spatial characteristics of $2 \mathrm{~m}$ temperature, $2 \mathrm{~m}$ specific humidity, and the $10 \mathrm{~m}$ wind speed distribution from forecasts was evaluated against observations through statistic metrics of mean bias and the root mean square error (RMSE). They are defined as:

$$
\begin{aligned}
\text { Bias } & =\frac{1}{n} \sum_{i=1}^{n}\left(F_{i}-O_{i}\right) \\
\text { RMSE } & =\sqrt{\frac{1}{n} \sum_{i=1}^{n}\left(F_{i}-O_{i}\right)^{2}}
\end{aligned}
$$

where $F_{i}$ represents the value in the $i$ th forecast gridded point and $Q_{i}$ is the corresponding observations. The closer the bias value is to 0 and the smaller the RMSE value is, the better the prediction is.

Table 1 shows the bias and RMSE of the average temperature of $2 \mathrm{~m}$, the specific humidity of $2 \mathrm{~m}$ and the wind speed of $10 \mathrm{~m}$ over the black rectangular boxes including urban and suburban areas in Beijing at 0900 UTC. It was predicted by two experiments initialized at 0600 UTC on 4 May 2019 prior to precipitation. Both experiments overestimate the observed $2 \mathrm{~m}$ temperature, and the bias is positive. Both the bias and RMSE in the MWRPS test are smaller than those in the Control test. The $2 \mathrm{~m}$ temperature forecast is closer to the actual observation, indicating better forecast performance. The $2 \mathrm{~m}$ specific humidity is dry in the Control test, but wet in the MWRPS test which has slightly large RMSE. In light of $10 \mathrm{~m}$ wind speed, the MWRPS test effectively improves the large wind speed forecast bias spotted in the Control test. To sum up, although in the MWRPS test the forecast error of $2 \mathrm{~m}$ specific humidity increases, the test addresses the warm bias of $2 \mathrm{~m}$ temperature and large bias of $10 \mathrm{~m}$ wind speed, and improves the forecast performance of surface meteorological elements at 0900 UTC, thus laying a good foundation for the simulated urban precipitation-free process. The bias and RMSE of the 1-h accumulated precipitation are compared in Control and MWRPS experiment initialized at 0600 UTC over the urban and suburban areas in Beijing. It also shows the improvement in the forecast with the ground-based microwave radiometer data assimilation.

Table 1. Bias and RMSE comparison of the simulated and observed surface temperature, specific humidity, and wind speed.

\begin{tabular}{ccccccc}
\hline \multirow{2}{*}{ Experiment } & \multirow{2}{*}{$\mathbf{m}$ Temperature $\left({ }^{\circ} \mathbf{C}\right)$} & \multicolumn{2}{c}{$\begin{array}{c}\text { m Specific Humidity } \\
(\mathbf{g} / \mathbf{k g})\end{array}$} & \multicolumn{2}{c}{$\mathbf{1 0} \mathbf{~}$ Wind Speed(m/s) } \\
\hline & Bias & RMSE & Bias & RMSE & Bias & RMSE \\
\hline Control & 1.65 & 1.67 & -0.43 & 0.59 & 1.21 & 1.32 \\
\hline MWRPS & 1.05 & 1.14 & 0.74 & 0.78 & -0.32 & 0.59 \\
\hline
\end{tabular}

Finally, the K-index simulated by the two experiments before the belt-shaped echo splitting is analyzed. It represents the atmospheric convection potential (warmth and humidity degree in the middle and lower layers and atmospheric stability) and has certain guiding significance for the prediction. The K-index is defined as:

$$
K=\left(T_{850}-T_{500}\right)+T d_{850}-\left(T_{700}-T d_{700}\right)
$$

where $T$ represents temperature and $T d$ represents dew point temperature, the value 850, 500 , and 700 is the corresponding isobaric surfaces of $850 \mathrm{hPa}, 500 \mathrm{hPa}$, and $700 \mathrm{hPa}$. In this formula, the first term represents the temperature drop rate, the second term represents the water vapor condition in the lower layer, and the third term represents the saturation degree in the middle layer. Therefore, the K-index represents the thermal instability in the middle and low layers and the water vapor saturation in the layer of $700 \mathrm{hPa}$. The K-index can reflect the stratification stability of atmosphere [49]. 
The larger the K-index is, the more unstable the stratification is. The higher the Kvalue is, the more likely convection is to occur [50], and the more unstable the stratification is. Generally, the stratification is rather unstable when the $\mathrm{K}$-index is higher than $35^{\circ} \mathrm{C}$. Figure $12 \mathrm{a}, \mathrm{b}$ show that the area with $\mathrm{K}$-index greater than $35^{\circ} \mathrm{C}$ in Beijing in the MWRPS test is smaller than that in the Control test. This shows that the structure of the background field is adjusted with the assimilated data of the ground-based microwave radiometers. The unstable energy in the middle and lower atmosphere in Beijing is reduced, the potential of convection occurrence and development is reduced, and the occurrence of precipitation is suppressed, so it can better predict the situation of no precipitation in urban area at 1000 UTC (Figure 7).
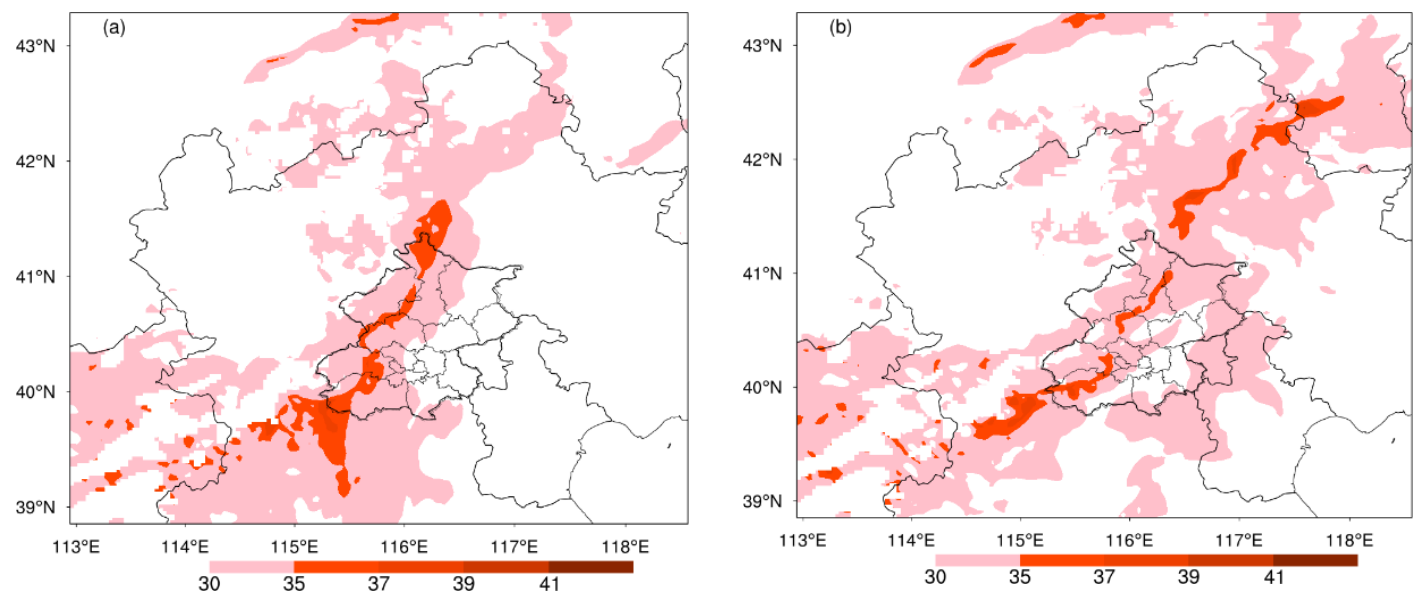

Figure 12. K-index at 0900 UTC on 4 May 2019 simulated by Control test at (a) and MWRPS test at (b) initialized at 0600 UTC before belt-shaped echo splitting.

While the K-index in the Control test at 0900 UTC is stronger than that in the MWRPS test in Baoding, Hebei province where precipitation intensity is high at 1000 UTC. The coverage area above $35^{\circ} \mathrm{C}$ is larger, resulting in the precipitation intensity predicted by the Control test at 1000 UTC being one level higher than that observed (Figures 7 and 12). For the K index, MWRPS experiment outperforms the Control experiment before the start of rainfall, it also has a better indication for forecasting the precipitation bifurcation.

\section{Conclusions}

In view of the belt-shaped convection echo splitting process in Beijing on 4 May 2019, the RMASPS-ST was used to explore whether the data assimilation of the ground-based microwave radiometers with high spatial and temporal resolution in Beijing could improve prediction. The two groups of experiments with and without the assimilation of MWRPS data were conducted in 3-h cycling runs. The simulation results for this rainfall bifurcation case obtained from the model system are verified. The experimental results show that the data assimilation of ground-based microwave radiometers in Beijing did improve the prediction of precipitation and echo, and better predicted the echo splitting process. The main conclusions are as follows:

(1) Assimilating the ground-based microwave radiometer data can improve the initial field to a certain extent. In view of this process, the vertical structure configuration of temperature field and humidity field was improved, which plays an important role in correcting the forecast bias of the model, addressing the deficiency of the model to a certain extent. The RMAPS-ST model system can provide a good simulation of the selected rainfall case assimilating the MWRPS data in Beijing. It can prominently reproduce the observed urban heat island of the main urban area in Beijing prior to the start of this rainfall, thus reproducing the forecast of short-term cumulative precipitation bifurcation in the urban area. The simulated precipitation, radar reflec- 
tivity and surface temperature, specific humidity, and wind speed are all closer to the observation compared to the Control experiment. The urban effect on rainfall in Beijing cannot be neglected;

(2) Different assimilation cycles have their corresponding improvement impacts on the initial field. The closer the assimilation cycle is, the more effective the precipitation forecast is. The MWRPS test valid from 0600 UTC has the best prediction effect, which is attributed to the thermodynamic condition under which the ground-based microwave radiometer data can be adjusted in time by cyclic assimilation. After the data of ground-based microwave radiometers are assimilated, the observed weak heat island phenomenon is better reproduced. The simulated surface temperature, specific humidity, and wind speed are also closer to the observation prior to the start of rainfall. The model not only prominently improves the forecast of precipitation distribution, but also makes the precipitation intensity prediction closer to the actual situation, and accurately predicts the process of belt-shaped echo splitting and precipitation bifurcation process in Beijing urban area;

(3) The belt-shaped convection echo splitting process in Beijing on 4 May 2019 shows that the assimilation of ground-based microwave radiometer data can improve the numerical prediction of this process, and makes a positive contribution to improving the simulation of precipitation in this belt-shaped convection splitting process. It indicates that the assimilation of ground-based microwave radiometer data have a bright application prospect in numerical models. Assimilating MWRPS data is of great importance for numerical models, improving the quality of the initial conditions and the subsequent forecasts. This rainfall event can also help us understand the effect of urban surface on the rainfall system under weak urban heat island conditions.

These conclusions are based on the rainfall bifurcation case occurred in the urban area of Beijing. Further investigation on the impact of assimilating ground-based microwave radiometer data on forecasts of the RMAPS-ST will continue. In addition, more sophisticated and advanced data assimilation method, such as the hybrid variational-ensemble approach and the data-driven machine learning method will hopefully further improve the effect of MWRPS data assimilation. However, conclusions from this study would be valuable for further understanding and application in regional numerical weather prediction models. Since the present study focused on only one case, the results may not be completely applicable to cases of other weather systems. More cases will be investigated to study the application of assimilation of ground-based microwave radiometer data in the future. In this way, we can have more insightful understanding of the impact of assimilation of ground-based microwave radiometer data on forecast.

Author Contributions: Conceptualization, B.L., Y.Q. and S.F.; methodology, Y.Q. and S.F.; software, Y.Q. and J.M.; validation, Y.Q.; formal analysis, Y.Q. and S.F.; computing resources, C.G. and S.Z.; writing-original draft preparation, Y.Q.; writing—review and editing, S.F., Y.Q. and C.G.; supervision, S.F.; funding acquisition, S.F. and Y.Q. All authors have read and agreed to the published version of the manuscript.

Funding: This research was funded by the National Key Technologies Research and Development Program of China (2017YFC1501704), Key Laboratory for Cloud Physics of China Meteorological Administration LCP/CMA (2020Z007), National Natural Science Foundation of China (42005124), and the Key Open Experimental Project of Atmospheric Exploration of China Meteorological Administration (KLAS201701).

Data Availability Statement: The ground-based microwave radiometers data can be available from Meteorological Observation Center of China Meteorological Administration.

Acknowledgments: We thank RMAPS-ST Authority for code support and sharing valuable data. We acknowledge Meteorological Observation Center of China Meteorological Administration for the ground-based microwave radiometers data.

Conflicts of Interest: The authors declare no conflict of interest. 


\section{References}

1. Westwater, E.R. Ground-based Microwave Remote Sensing of Meteorological Variables. In Atmospheric Remote Sensing by Microwave Radiometry; Janssen, M.A., Ed.; Wiley: New York, NY, USA, 1993; pp. 145-213.

2. Lohnert, U.; Maier, O. Operational Profiling of Temperature Using Ground-based Microwave Radiometry at Payerne: Prospects and Challenges. Atmos. Meas. Tech. 2012, 5, 1121-1134. [CrossRef]

3. Martinet, P.; Cimini, D.; De Angelis, F.; Canut, G.; Unger, V.; Guillot, R.; Tzanos, D.; Paci, A. Combining ground-based microwave radiometer and the AROME convective scale model through 1DVAR retrievals in complex terrain: An Alpine valley case study. Atmos. Meas. Tech. 2017, 10, 3385-3402. [CrossRef]

4. Cimini, D.; Campos, E.; Ware, R.; Albers, S.; Giuliani, G.; Oreamuno, J.; Joe, P.; Koch, S.E.; Cober, S.; Westwate, E. Thermodynamic Atmospheric Profiling during the 2010 Winter Olympics Using Ground-based Microwave Radiometry. IEEE Trans. Geosci. Remote Sens. 2011, 49, 4959-4969. [CrossRef]

5. Cimini, D.; Nelson, M.; Guldner, J.; Ware, R. Forecast Indices from a Ground-based Microwave Radiometer for Operational Meteorology. Atmos. Meas. Tech. 2015, 8, 315-333. [CrossRef]

6. Liu, S.; Heygster, G.; Zhang, S.P. Comparison of CloudSat Cloud Liquid Water Paths in Arctic Summer Using Ground-Based Microwave Radiometer. J. Ocean. Univ. China 2010. (In Chinese) [CrossRef]

7. Qiu, J.H.; Chen, H.B.; Wang, P.C.; Liu, Y.; Xia, X.A. Recent Progress in Atmospheric Observation Research in China. Adv. in Atmos. Sci. 2007, 24, 940-953. [CrossRef]

8. Illingworth, A.J.; Cimini, D.; Haefele, A.; Haeffelin, M.; Hervo, M.; Kotthaus, S.; Löhnert, U.; Martinet, P.; Mattis, I.; O'Connor, E.J.; et al. How Can Existing Ground-Based Profiling Instruments Improve European Weather Forecasts? Bull. Am. Meteor. Soc. 2019. [CrossRef]

9. Guo, L.J.; Guo, X.L.; Fang, C.G.; Zhu, S.C. Observation analysis on characteristics of formation, evolution and transition of a long-lasting severe fog and haze episode in North China. Sci. China Earth Sci. 2015, 58, 329-344. (In Chinese) [CrossRef]

10. Hartung, D.C.; Otkin, J.A.; Petersen, R.A.; Turner, D.D.; Feltz, W.F. Assimilation of Surface-based Boundary-layer Profiler Observations during a Cool Season Weather Event Using an Observing System Simulation Experiment. Part II: Forecast Assessment. Mon. Weather Rev. 2011, 139, 2327-2346. [CrossRef]

11. Vandenberghe, F.; Ware, R. Four-dimensional variational assimilation of ground-based microwave observations during a winter fog event. In Proceedings of the International Workshop on GPS Meteorology, International Symposium on Atmospheric Sensing with GPS, Tsukuba, Japan, 14-17 January 2003.

12. Caumont, O.; Cimini, D.; Lohnert, U.; Alados-Arboledas, L.; Bleisch, R.; Buffa, F.; Ferrario, M.E.; Haefele, A.; Huet, T.; Madonna, F. Assimilation of Humidity and Temperature Observations Retrieved from Ground-based Microwave Radiometers into a Convective-scale NWP Model. Q. J. R. Meteorol. Soc. 2016, 142, 2692-2704. [CrossRef]

13. Otkin, J.A.; Hartung, D.C.; Turner, D.D.; Petersen, R.A.; Feltz, W.F.; Janzon, E. Assimilation of surface-based boundary layer profiler observations during a cool-season weather event using an observing system simulation experiment. Part I: Analysis impact. Mon. Weather Rev. 2011, 139, 2309-2326. [CrossRef]

14. Wang, Y.H.; Lai, A.W.; Zhao, Y.C. Numerical Study of an Excessive Heavy Rain Event by Assimilating Humidity Profiles Retrieved from Ground-based Microwave Radiometers. Torrential Rain Disasters 2010, 29, 201-207. (In Chinese)

15. Wenying, H.; Chen, H.; Li, J. Influence of assimilating ground-based microwave radiometer data into the WRF model on precipitation. Atmos. Ocean. Sci. Lett. 2020, 13, 107-112.

16. Yin, J.B.; Guo, S.L.; Gu, L.; Zeng, Z.Y.; Liu, D.D.; Chen, J.; Shen, Y.J.; Xu, C.Y. Blending multi-satellite, atmospheric reanalysis and gauge precipitation products to facilitate hydrological modelling. J. Hydrol. 2021, 593, 125878. [CrossRef]

17. Zhang, L.; Li, X.; Zheng, D.; Zhang, K.; Ma, Q.; Zhao, Y.; Ge, Y. Merging multiple satellite-based precipitation products and gauge observations using a novel double machine learning approach. J. Hydrol. 2021, 594, 125969. [CrossRef]

18. Kumar, A.; Ramsankaran, R.; Brocca, L.; Munoz-Arriola, F. A Machine Learning Approach for Improving Near-Real-Time Satellite-Based Rainfall Estimates by Integrating Soil Moisture. Remote Sens. 2019, 11, 2221. [CrossRef]

19. Bhuiyan, M.A.E.; Yang, F.; Biswas, N.K.; Rahat, S.H.; Neelam, T.J. Machine learning-based error modeling to improve GPM IMERG precipitation product over the Brahmaputra river basin. Forecasting 2020, 2, 248-266. [CrossRef]

20. Yagmur, D.; Bhuiyan, M.A.E.; Anagnostou, E.; Kalogiros, J.; Anagnostou, M.N. Modeling Level 2 Passive Microwave Precipitation Retrieval Error Over Complex Terrain Using a Nonparametric Statistical Technique. IEEE Trans. Geosci. Remote Sens. 2020. [CrossRef]

21. Collard, A.; Hilton, F.; Forsythe, M.; Candy, B. From Observations to Forecasts-Part 8: The use of satellite observations in numerical weather prediction. Weather 2011, 66, 31-36. [CrossRef]

22. Bromwich, D.H.; Monaghan, A.J.; Manning, K.W.; Powers, J.G. Real-time forecasting for the Antarctic: An evaluation of the Antarctic Mesoscale Prediction System (AMPS). Mon. Weather Rev. 2005, 133, 579-603. [CrossRef]

23. Wille, J.D.; Bromwich, D.H.; Cassano, J.J.; Nigro, M.A.; Mateling, M.E.; Lazzara, M.A. Evaluation of the AMPS boundary layer simulations on the ross ice shelf, Antarctica, with unmanned aircraft observations. J. Appl. Meteorol. Climatol. 2017, 56, 2239-2258. [CrossRef]

24. Atlaskin, E.; Vihma, T. Evaluation of NWP results for wintertime nocturnal boundary-layer temperatures over Europe and Finland. Quart. J. R. Meteorol. Soc. 2012, 138, 1440-1451. [CrossRef] 
25. Kalnay, E. Atmospheric Modeling, Data Assimilation and Predictability; Press Syndicate of the University of Cambridge: London, UK, 2003.

26. Sun, J.; Trier, S.B.; Xiao, Q.; Weisman, M.L.; Wang, H.; Ying, Z.; Xu, M.; Zhang, Y. Sensitivity of 0 12-h warm-season precipitation forecasts over the Central United States to model initialization. Weather Forecast. 2012, 27, 832-855. [CrossRef]

27. Xu, D.; Min, J.; Shen, F.; Ban, J.; Chen, P. Assimilation of MWHS radiance data from the FY-3B satellite with the WRF Hybrid3DVAR system for the forecasting of binary typhoons. J. Adv. Model. Earth Syst. 2016, 8, 1014-1028. [CrossRef]

28. Barker, D.; Huang, W.; Guo, Y.R.A. Three-dimensional Variational (3DVAR) Data Assimilation System for Use with MM5; NCAR Tech Note: Boulder, CO, USA, 2003; pp. 1-68.

29. Barker, D.; Huang, W.; Guo, Y.R.; Bourgeois, J.A.; Xiao, N.Q. A three-dimensional variational data assimilation system for MM5: Implementation and initial results. Mon. Weather Rev. 2004, 132, 897-914. [CrossRef]

30. Barker, D.; Huang, X.Y.; Liu, Z.; Auligné, T.; Zhang, X.; Rugg, S.; Ajjaji, R.; Bourgeois, A.; Bray, J.; Chen, Y. The weather research and forecasting (WRF) model's community variational/ensemble data assimilation system: WRFDA. Bull. Am. Meteorol. Soc. 2012, 93, 831-843. [CrossRef]

31. Fan, S.; Wang, H.L.; Chen, M.; Gao, H. Study of the data assimilation of radar reflectivity with the WRF 3DVar. Acta Meteor. Sin. 2013, 71, 527-537. (In Chinese)

32. Wilson, J.; Feng, Y.; Chen, M.; Roberts, R.D. Nowcasting challenges during the Beijing Olympics: Successes, failures, and implications for future nowcasting systems. Weather Forecast. 2010, 25, 1691-1714. [CrossRef]

33. Zhang, L.; Ni, Y.Q. Four-Dimensional Variational Data Assimilation of Radar Radial Velocity Observations. Chin. J. Atmos. Sci. 2006, 30, 433-440. (In Chinese)

34. Qi, Y.J.; Chen, M.; Zhong, J.Q.; Fan, S.Y.; Liu, R.T.; Guo, C.W. Effect evaluation of short-term forecast of surface meteorological elements by using RMAPS-ST coupled urban canopy model. J. Arid Meteorol. 2020, 38, 859-868. (In Chinese)

35. Xie, Y.H.; Shi, J.C.; Fan, S.Y.; Dou, Y.J.; Ji, D. Impact of radiance data assimilation on the prediction of heavy rainfall in RMAPS: A case study. Remote Sens. 2018, 10, 1380. [CrossRef]

36. Xie, Y.H.; Chen, M.; Shi, J.C.; Fan, S.Y.; He, J.; Dou, Y.J.; Ji, D. Impacts of Assimilating ATMS Radiances on Heavy Rainfall Forecast in RMAPS-ST. Remote Sens. 2020, 12, 1147. [CrossRef]

37. Hong, S.Y.; Noh, Y.; Dudhia, J. A new vertical diffusion package with an explicit treatment of entrainment processes. Mon. Weather Rev. 2006, 134, 2318-2341. [CrossRef]

38. Pincus, R.; Mlawer, E.J.; Oreopoulos, L.; Ackerman, A.S.; Baek, S.; Brath, M.; Buehler, S.A.; Cady-Pereira, K.E.; Cole, J.N.S.; Dufresne, J.L. Radiative flux and forcing parameterization error in aerosol-free clear skies. Geophys. Res. Lett. 2015, 42, 5485-5492. [CrossRef]

39. Mlawer, E.J.; Taubman, S.J.; Brown, P.D.; Iacono, M.J.; Clough, S.A. Radiative transfer for inhomogeneous atmospheres: RRTM, a validated correlated-k model for the longwave. J. Geophys. Res. 1997, 102, 16663-16682. [CrossRef]

40. Sun, J.; Wang, H.; Tong, W.; Zhang, Y.; Xu, D. Comparison of the impacts of momentum control variables on high-resolution variational data assimilation and precipitation forecasting. Mon. Weather Rev. 2015, 144, 149-169. [CrossRef]

41. Parrish, D.F.; Derber, J.C. The national meteorological center's spectral statistical-interpolation analysis system. Mon. Weather Rev. 1992, 120, 1747-1763. [CrossRef]

42. Hsiao, L.F.; Chen, D.S.; Kuo, Y.H.; Guo, Y.R.; Yeh, T.C.; Hong, J.S.; Fong, C.T. Application of WRF 3DVAR to operational typhoon prediction in Taiwan: Impact of outer loop and partial cycling approaches. Weather Forecast. 2012, 27, 1249-1263. [CrossRef]

43. Zhang, Y.; Miao, S.; Dai, Y.; Bornstein, R. Numerical simulation of urban land surface effects on summer convective rainfall under different UHI intensity in Beijing. J. Geophys. Res. Atmos. 2017, 122, 7851-7868. [CrossRef]

44. Wang, Y.; Zhao, X.; Zuo, L.; Zhang, Z.; Wang, X.; Yi, L.; Liu, F.; Xu, J. Spatial Differentiation of Land Use and Landscape Pattern Changes in the Beijing-Tianjin-Hebei Area. Sustainability 2020, 12, 3040. [CrossRef]

45. Zhang, S.; Huang, G.; Qi, Y.J.; Jia, G.S. Impact of urbanization on summer rainfall in Beijing-Tianjin-Hebei metropolis under different climate backgrounds. Theor. Appl. Climatol. 2018, 133, 1093-1106. [CrossRef]

46. Lin, D.W.; Bueh, C.L.; Xie, Z.W. A study on the coupling relationships among Pacific sea surface temperature and summer rainfalls over North China and India. Chin. J. Atmos. Sci. 2018, 42, 1175-1190. (In Chinese)

47. Dou, J.; Wang, Y.; Bornstein, R.D.; Miao, S. Observed spatial characteristics of Beijing urban climate impacts on summer thunderstorms. J. Appl. Meteorol. Climatol. 2015, 54, 94-105. [CrossRef]

48. Bornstein, R.D. Establishment of meso-met modeling case studies to evaluate the relative roles of urban dynamics and aerosols on summer thunderstorms: A proposal. In Proceedings of the 18th Conference on Planned and Inadvertent Weather Modification, and Third Symposium on Aerosol-Cloud-Climate Interactions, San Jose, CA, USA, 27 January 2011.

49. Song, H.O.; Wang, Y.H.; Gu, S.Q.; Liu, J.X. An experiment on forecasting metaphase precipitation using K-exponent and Tot-exponent. Sci. Meteorol. Sin. 2002, 22, 242-246. (In Chinese)

50. Gao, Y.D.; Wan, Q.L.; Xue, J.S. Effects of assimilating radar rainfall rate estimation on torrential rain forecast. J. Appl. Meteorol. Sci. 2015, 26, 45-56. (In Chinese) 